Tropical Journal of Pharmaceutical Research January 2017; 16 (1): 17-29

ISSN: $1596-5996$ (print); 1596-9827 (electronic)

(C) Pharmacotherapy Group, Faculty of Pharmacy, University of Benin, Benin City, 300001 Nigeria.

All rights reserved.

Available online at http://www.tjpr.org

Original Research Article

http://dx.doi.org/10.4314/tjpr.v16i1.4

\title{
Tangeretin sensitises human lung cancer cells to TRAIL- induced apoptosis via ROS-JNK/ERK-CHOP pathway- mediated up-regulation of death receptor 5
}

\author{
Xi Liu, Lei Chen, Yang Liu and Tao Zhang* \\ Department of Thoracic Surgery, Chinese PLA General Hospital, Beijing, 100853, China
}

*For correspondence: Email: zhangtaoasd01@126.com

Received: 11 February 2016

Revised accepted: 5 December 2016

\begin{abstract}
Purpose: To investigate the efficacy of tangeretin, a bioactive flavonoid, as an enhancer of tumour necrosis factor-related apoptosis-inducing ligand (TRAIL)-induced apoptosis in human lung cancer cells (H1299 and H1975).

Methods: H1299 and H1975 cells were exposed to tangeretin (25, 50, or $100 \mu \mathrm{M})$, and its effect on cell viability was assessed by MTT assay. The cytotoxic effects of tangeretin in combination with TRAIL (25 $\mathrm{ng} / \mathrm{mL}$ ) were determined by live/dead assay and annexin $V$ staining. Intracellular levels of reactive oxygen species (ROS) were determined by DHFDA-flow cytometry analysis. Western blotting was performed to assess the expression of death receptors, apoptosis pathway proteins, JNK and ERK1/2. The cell surface expression of death receptors was determined. RT-PCR was performed to assess the expression of death receptor 5 and CEBP homologous protein (CHOP) mRNA. The cytotoxic effects of tangeretin in the presence of DR5, CHOP siRNA and TRAIL were also detected.

Results: MTT assay revealed that tangeretin exerted potent cytotoxic effects and, in combination with TRAIL, exhibited striking apoptosis. Down-regulation of cell survival proteins $(B c-2, B C l-x L$, survivin, $x I A P, C-I A P-1$, and $c-I A P-2)$ and elevated expression of Bax and caspases 3, 8, and 9 were observed upon tangeretin exposure. The expression of death receptors DR4 and DR5 was highly up-regulated by tangeretin, while that of decoy receptors DcR1 and DcR2 was down-regulated. DR5 and CHOP siRNA transfection suggested the involvement of CHOP in tangeretin-mediated up-regulation of DR5, leading to more pronounced apoptotic effects. Tangeretin increased ROS levels and effectively caused activation of the mitogen-activated protein kinases JNK, ERK, and p38MAPKs. Expression analysis in the presence of specific MAPK inhibitors suggested the involvement of JNK and ERK in tangeretinmediated TRAIL sensitisation.

Conclusions: Tangeretin induces death receptors and enhances TRAIL-induced apoptosis through upregulation of the ROS-JNKJERK-CHOP pathways.
\end{abstract}

Keywords: Apoptosis, Death receptors, Lung cancer, Tangeretin, Reactive oxygen species, Tumour necrosis factor-related apoptosis-inducing ligand

Tropical Journal of Pharmaceutical Research is indexed by Science Citation Index (SciSearch), Scopus, International Pharmaceutical Abstract, Chemical Abstracts, Embase, Index Copernicus, EBSCO, African Index Medicus, JournalSeek, Journal Citation Reports/Science Edition, Directory of Open Access Journals (DOAJ), African Journal Online, Bioline International, Open-J-Gate and Pharmacy Abstracts

\section{INTRODUCTION}

Despite immense progression in the field of medicine, cancer remains a major threat to human health. Lung cancer is a prominent cause of cancer-related death worldwide [1]. Non-small cell lung cancer (NSCLC), the primary type of lung cancer, accounts for approximately $85 \%$ of all cases, and small cell lung cancer (SCLC) accounts for $15 \%$ [2]. Despite advancements in chemotherapy and radiation therapy, the long- 
term survival of patients with NSCLC remains low, with a 5-year survival rate of about $15 \%$ [3]. Induction of apoptosis is crucial in cancer therapy. Much research has recently focused on strategies that specifically target molecules directly involved in the apoptotic pathways, thereby enhancing cancer cell death.

Tumour necrosis factor-related apoptosisinducing ligand (TRAIL or Apo2 ligand) is a member of the tumour necrosis factor superfamily. TRAIL selectively induces apoptosis of cancer cells with negligible effects on normal cells [4,5]. TRAIL exerts its effects through interaction of its ligands with two membrane receptors, TRAIL-R1 (DR4) and TRAIL-R2 (DR5) [6]; the antagonistic transmembrane decoy receptor (DcR)-1 and DcR2 [7]; and the soluble receptor osteoprotegerin, which lacks the transmembrane domain [8].

The interaction of TRAIL with DR4 and DR5 leads to an association with Fas-associated death domain and caspase-8, forming a deathinducing signal complex that results in activation of an initiator caspase (caspase-8) and effector caspases (caspases-3, -6, -7, and -9), thereby inducing apoptosis $[9,10]$. TRAIL-induced preferential apoptosis of cancer cells makes this agent crucial in cancer treatment. However, many cancer cells acquire resistance to TRAIL by multiple mechanisms [11]. The mechanisms underlying TRAIL resistance include downregulation of DRs and up-regulation of decoy receptors [11,12] and various anti-apoptotic proteins, including cellular FLICE-like inhibitory protein (cFLIP $(L))$, which competes with caspase-8 [13] and inhibitor of apoptosis proteins (IAPs) [14]. Thus, identification of TRAIL sensitizers that will overcome TRAIL resistance is a valuable approach in cancer therapy.

Several studies have demonstrated that plantderived compounds effectively sensitise cancer cells to TRAIL-induced apoptosis $[15,16]$. Tangeretin $\quad(4 ', 5,6,7,8$-pentamethoxyflavone), widely present in citrus fruits, possesses numerous bioactive properties, such as antiinflammatory [17], anti-proliferative [18], and neuroprotective [19] activities. In the present study, we investigated whether tangeretin effectively sensitises and enhances human lung cancer cells to TRAIL-induced apoptosis.

\section{EXPERIMENTAL}

\section{Cell lines}

The human lung cancer cells $\mathrm{H} 1299$ and $\mathrm{H} 1975$ were obtained from ATCC and maintained according to the manufacturer's instructions. In brief, the cells were cultured in RPMI 1640 medium (Invitrogen, Carlsbad, CA, USA) supplemented with $10 \%$ foetal bovine serum, 100 units $/ \mathrm{mL}$ of penicillin, and $100 \mu \mathrm{g} / \mathrm{mL}$ of streptomycin.

\section{Chemicals and reagents}

Tangeretin (Sigma-Aldrich, St. Louis, Mo, USA) and human trail (Peprotech, Rocky Hill, NJ, USA) were used. A cell apoptosis elisa detection kit was obtained from Roche. 2',7'-dichlorofluorescein diacetate (dcf-da) (Molecular Probes Inc., Eugene, OR, USA) was used in the study. Antibodies to $\mathrm{Bcl}-\mathrm{xL}$, $\mathrm{Bcl}-2$, survivin, Bax, cFLIP, CEBP homologous protein (CHOP), XIAP, clAP-1, clAP-2, caspase-3, caspase-8, caspase-9, DcR1, DcR2, DR4, DR5 (Cell Signaling Technology, Danvers, MA, USA), JNK, phospho-JNK, ERK1/2, phospho-ERK1/2, p38, phospho-p38, and $\beta$-actin (Santa Cruz Biotechnology, Santa Cruz, CA,USA) were used for expression analysis. Other chemicals and reagents used in the study were of analytical grade and were purchased from Sigma-Aldrich unless otherwise mentioned.

\section{Cell viability assay}

The cytotoxic effects of tangeretin $(25-100 \mu \mathrm{M})$ on human lung cancer cells (H1299 and H1975) were assessed by 3-(4,5-dimethylthiazol-2-yl)2,5-diphenyltetrazolium bromide (MTT) assay. In brief, the cells were seeded into 96-well plates $\left(0.5 \times 10^{6}\right.$ cells/well $)$ and incubated for $24 \mathrm{~h}$ followed by exposure to various concentrations of tangeretin for $24 \mathrm{~h}$. After incubation, the cells were treated with MTT. After $4 \mathrm{~h}$, the formazan crystals were dissolved in DMSO and the absorbance was measured at $570 \mathrm{~nm}$ using a Multiskan Spectrum (Thermo Electron Co., Vantaa, Finland).

\section{Live/dead assay}

A live/dead assay was performed to further assess apoptosis. The experiment was carried out using a Live/Dead assay kit (Invitrogen). The assay employs calcein-AM, a non-fluorescent polyanionic dye that determines the membrane integrity as a measure of cell viability. In brief, the cells with tangeretin $(25,50$ or $100 \mu \mathrm{M})$ and/or TRAIL $(25 \mathrm{ng} / \mathrm{mL})$ were stained with Live/Dead reagent $(5 \mu \mathrm{mol} / \mathrm{L}$ ethidiumhomodimer and 5 $\mu \mathrm{mol} / \mathrm{L}$ calcein-AM). The cells were then incubated at $37^{\circ} \mathrm{C}$ for $30 \mathrm{~min}$. Apoptosis was assessed by measuring the fluorescence under a 
fluorescence microscope (Labophot-2; Nikon, Tokyo, Japan). Live cells retained the calcein-AM dye and produced intense green fluorescence, while the ethidiumhomodimerbecame bound to nucleic acids inside the dead cells and produced bright red fluorescence.

\section{Analysis of apoptosis by Annexin V assay}

Human lung carcinoma cells were incubated with tangeretin (50 or $100 \mu \mathrm{M}$ ) and/or TRAIL (25 $\mathrm{ng} / \mathrm{mL}$ ) for $24 \mathrm{~h}$, and apoptosis was detected using an Annexin V-FITC detection kit II (BD Biosciences Pharmingen, San Diego, CA, USA). After incubation, the cells were treated with $5 \mu \mathrm{L}$ annexin V-FITC reagent, incubated for $30 \mathrm{~min}$ at room temperature, and analysed using a flow cytometer (FACS Calibur; BD Biosciences).

\section{Analysis of DR4 and DR5 expression}

The influence of tangeretin $(25,50$, and $100 \mu \mathrm{M})$ on the cell-surface expression of death receptors (DR4 and DR5) in the lung cancer cells was assessed using mouse anti-human DR4 or DR5 monoclonal antibodies conjugated with phycoerythrin (R\&D Systems,Minneapolis, MN, USA). Cells treated with tangeretin for $24 \mathrm{~h}$ were incubated with antibodies for $45 \mathrm{~min}$ at $4{ }^{\circ} \mathrm{C}$. The expression was analysed by flow cytometry [20].

\section{RT-PCR analysis}

The mRNA expression of DR5 and CHOP was assessed by performing RT-PCR. Total RNA was extracted from the cells after exposure to tangeretin $(25,50$, and $100 \mu \mathrm{M})$ for $24 \mathrm{~h}$ using TRIzol reagent (Invitrogen). The total RNA was amplified by PCR [21] using the following primers: DR5, sense 5'-AAGACCCTTGTG CTCGTTGTC-3' and anti-sense 5'-GACACATT CGATGTCACTCCA-3'; CHOP, sense 5'CAACTGCAGAGATGGCAGC TGA-3' and antisense 5'-CTGATGCTCCCAATT GTTCAT-3'; and glyceraldehyde-3-phosphate dehydrogenase (GAPDH), sense 5'-GTCTTCACCACCATGGAG3 ' and antisense 5'-CCACCCTGTTGCTGTAGC3'. The relative expression levels of $\mathrm{CHOP}$ and DR5 genes were normalised with the expression of GAPDH.

\section{Transfection with siRNA}

The influence of tangeretin on DR5 and CHOP expression following silencing with respective siRNA (Santa Cruz Biotechnology) was assessed. The H1299 and $\mathrm{H} 1975$ cells were transfected with siRNA oligonucleotides (30 $\mathrm{nmol} / \mathrm{L}$ ) using lipofectamine 2000 (Invitrogen) according to the manufacturer's instructions.
Following transfection, the cells were treated with tangeretin $(100 \mu \mathrm{M})$ for $12 \mathrm{~h}$ and incubated with TRAIL $(25 \mathrm{ng} / \mathrm{mL})$ for $24 \mathrm{~h}$ [22]. After these treatments, the cells were collected and analysed for expression using western blotting, and apoptosis was assessed by the Live/Dead assay.

\section{Measurement of reactive oxygen species}

To detect intracellular reactive oxygen species (ROS) in the lung cancer cells, the cells were treated with $20 \mu \mathrm{M}$ DCF-DA for $15 \mathrm{~min}$ at $37^{\circ} \mathrm{C}$. Following DCF-DA treatment, the cells were incubated with various concentrations of tangeretin $(25,50$, or $100 \mu \mathrm{M})$ for $30 \mathrm{~min}$. The increase in fluorescence resulting from the oxidation of DCF-DA to DCF was analysed by flow cytometry at $530 \mathrm{~nm}$ as previously described [23]. Data were analysed for at least 10,000 cells at a flow rate of 250 to 300 cells/s.

\section{Western blotting}

The cells treated with tangeretin $(25,50$, or 100 $\mu \mathrm{M})$ and/or TRAIL $(25 \mathrm{ng} / \mathrm{mL})$ for $24 \mathrm{~h}$ were subjected to western blot analysis to assess the expression of proteins. Western blot analysis was carried out as previously described by Yang et al [24]. Following treatment with tangeretin and TRAIL, the cells were incubated in $0.5 \mathrm{~mL}$ of icecold whole-cell lysate buffer $(5 \mathrm{M} \mathrm{NaCl}, 10 \%$ Nonidet P-40, $0.2 \mathrm{M}$ sodium orthovanadate, 0.1 M EGTA, $0.5 \mathrm{M}$ EDTA, $0.1 \mathrm{M}$ phenylmethylsulfonyl fluoride, $1 \mathrm{M}$ sodium fluoride, $1 \mathrm{M}$ HEPES $2 \mu \mathrm{g} / \mathrm{mL}$ aprotinin, and $2 \mu \mathrm{g} / \mathrm{mL}$ leupeptin) on ice for $30 \mathrm{~min}$. The isolated protein concentrations were determined using a Bio-Rad assay kit (Bio-Rad, Hercules, CA, USA). Equal amounts $(60 \mu \mathrm{g})$ of isolated proteins were fractionated using SDS-PAGE and transferred onto polyvinylidene fluoride membranes (Millipore, Billerica, MA, USA), following incubation with respective antibodies. The immunoreactive bands were detected and analysed using an ECL Advance western blot analysis system (Amersham Pharmacia Biotech Inc., Piscataway, NJ, USA). The band densities were normalised to those of control $\beta$-actin using anti- $\beta$-actin antibody (Cell Signaling Technology).

\section{Statistical analysis}

SPSS software (ver. 22.0; IBM Corp., Armonk, NY, USA) was used for analysis. The experimental data are given as means $\pm S D(n=$ 3 or 6). The means of the various groups were compared by one-way ANOVA followed by Duncan's multiple range test (DMRT) as a posthoc analysis. Differences with a $p$ value of $<0.05$ were considered statistically significant. 


\section{RESULTS}

\section{Tangeretin inhibited cancer cell proliferation}

Tangeretin at 25,50 , and $100 \mu \mathrm{M}$ significantly ( $p$ $<0.05$ ) inhibited the proliferation of $\mathrm{H} 1975$ and H1299 cells (Fig. 1). The cell viability percentage decreased in a concentration-dependent manner. The highest dose $(100 \mu \mathrm{M})$ exhibited maximum inhibitory effects as compared with the lower doses $(25$ and $50 \mu \mathrm{M})$.

\section{Tangeretin enhances TRAIL-induced apoptosis of lung cancer cells}

We also examined whether tangeretin was able to enhance and sensitise lung cancer cells to TRAIL-induced apoptosis by the Live/Dead assay and Annexin V staining. The Live/Dead assay was performed after exposure to 25,50 or $100 \mu \mathrm{M}$ tangeretin. Exposure to the 100- $\mu \mathrm{M}$ concentration resulted in a drastic increase in apoptosis (69.09\% of $\mathrm{H} 1299$ cells and $58.93 \%$ of $\mathrm{H} 1975$ cells) (Fig. 2). Tangeretin at the 100$\mu \mathrm{M}$ concentration induced higher apoptotic cell counts than did lower concentrations. Interestingly, however, combined exposure to TRAIL and tangeretin at $100 \mu \mathrm{M}$ resulted in a multi-fold increase in cytotoxicity. The apoptosis percentage increased to $81.19 \%$ in $\mathrm{H} 1299$ cells and $84.90 \%$ in $\mathrm{H} 1975$ cells (Figure 2), while TRAIL alone induced apoptosis of about 37.18 and $40.24 \%$ in H1299 and H1975 cells, respectively.
We further analysed the efficacy of tangeretin in enhancing TRAIL-induced apoptosis by Annexin $\mathrm{V}$ staining assay. The assay examines the integrity of the cell membrane as a measure of cell viability. The translocation of phosphatidylserine from the cytoplasmic interface to the extracellular surface of the membrane is a preliminary indicator of apoptosis. The results presented in Figure 3 show that tangeretin was able to markedly $(p<0.05)$ increase the apoptosis percentage with combined exposure to TRAIL and tangeretin at 50 and $100 \mu \mathrm{M}$ compared with exposure to either TRAIL or tangeretin. These observations suggest that tangeretin at the tested doses significantly enhanced sensitivity to TRAIL and improved TRAIL-induced apoptosis.

\section{Tangeretin potentially up-regulates the expression of DR4 and DR5}

Studies have shown that down-regulation or loss of DR4 and DR5 expression is a major mechanism involved in TRAIL resistance $[10,11]$. We observed significantly $(p<0.05)$ enhanced cell surface expression of DR4 and DR5 upon treatment with tangeretin in a dose-dependent manner (Fig. 4a). Furthermore, expression at the protein level was detected by western blot analysis. The results revealed similarly increased expression of DR4 and DR5 upon exposure to tangeretin (Fig. 4b), suggesting the efficacy of tangeretin in up-regulating the expression of DR4 and DR5, thereby increasing apoptosis. Additionally, $100 \mu \mathrm{M}$ of tangeretin increased the expression when compared with lower doses.

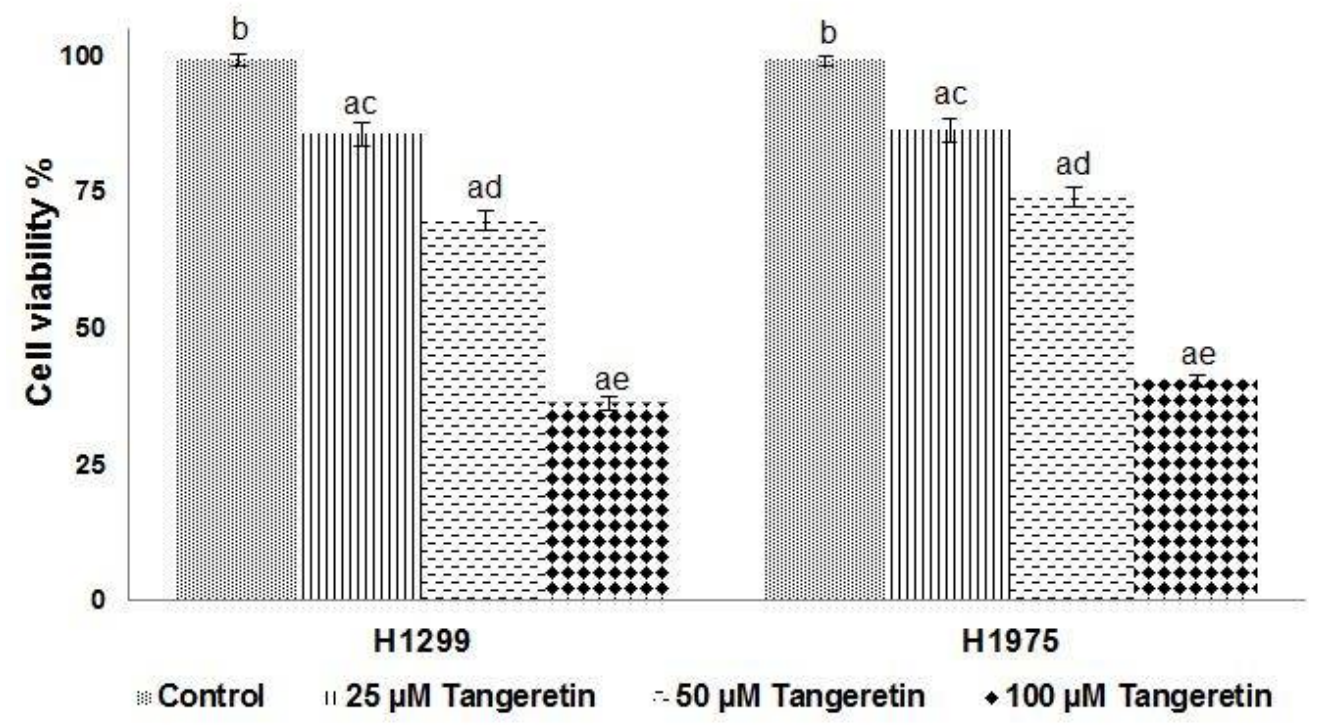

Figure 1: Cytotoxicity of various concentrations of tangeretin. Results are expressed as means $\pm \mathrm{SD}$ with $\mathrm{n}=6 . p$ $<0.05$ versus control, denoted by ${ }^{a} ;{ }^{b-e}$ denotes mean values within the same group that differ from each other at $p<0.05$ on one-way ANOVA and Duncan's multiple range test (DMRT) analysis 


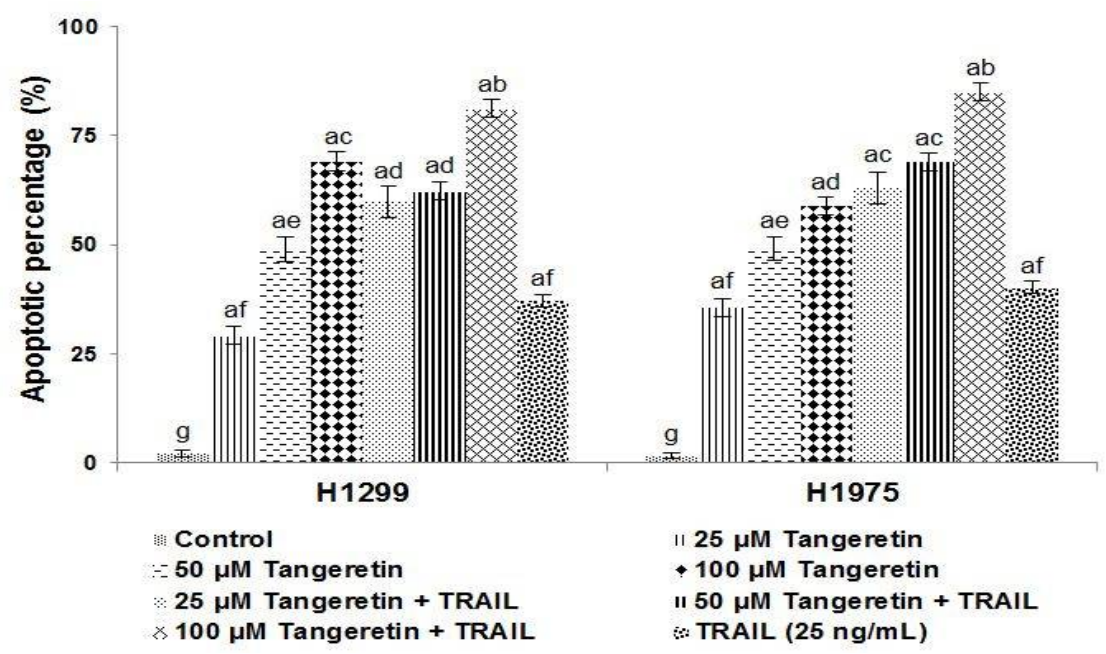

Figure 2: Tangeretin enhances apoptosis of $\mathrm{H} 1299$ and $\mathrm{H} 1975$ cells. Tangeretin in combination with tumour necrosis factor-related apoptosis-inducing ligand (TRAIL) enhanced apoptosis in a dose-dependent manner. Results are expressed as means \pm SD with $n=6 . p<0.05$ versus control, denoted by ${ }^{a} ;{ }^{b-e}$ denotes mean values within the same group that differ from each other at $p<0.05$ on one-way ANOVA and DMRT analysis

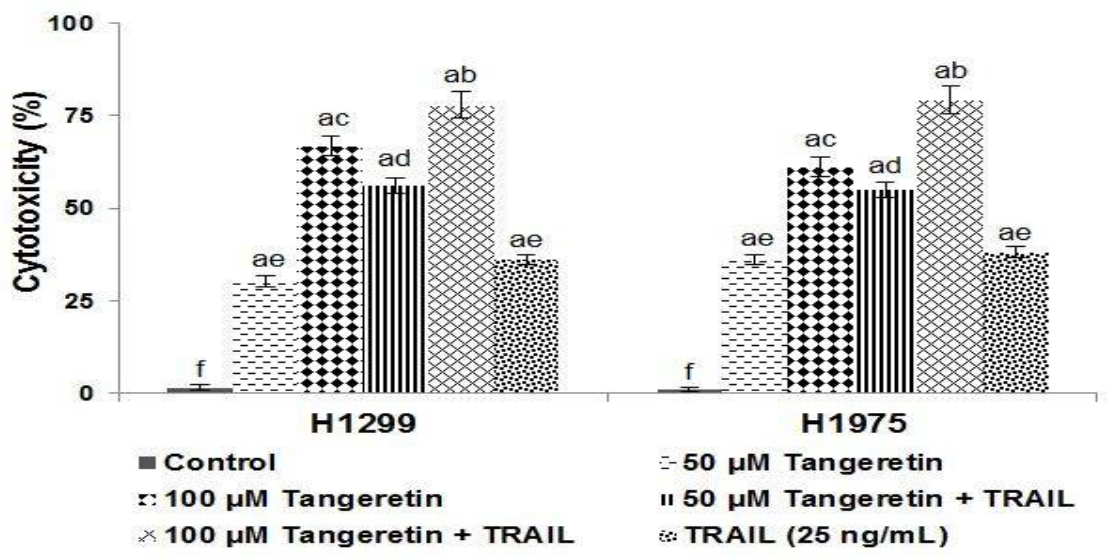

Figure 3: Tangeretin enhanced TRAIL-induced apoptosis. Results are expressed as means \pm SD with $n=6$. $p<$ 0.05 versus control, denoted by ${ }^{a} ;{ }^{b-f}$ denotes mean values within the same group that differ from each other at $p$ $<0.05$ on ANOVA and DMRT analysis
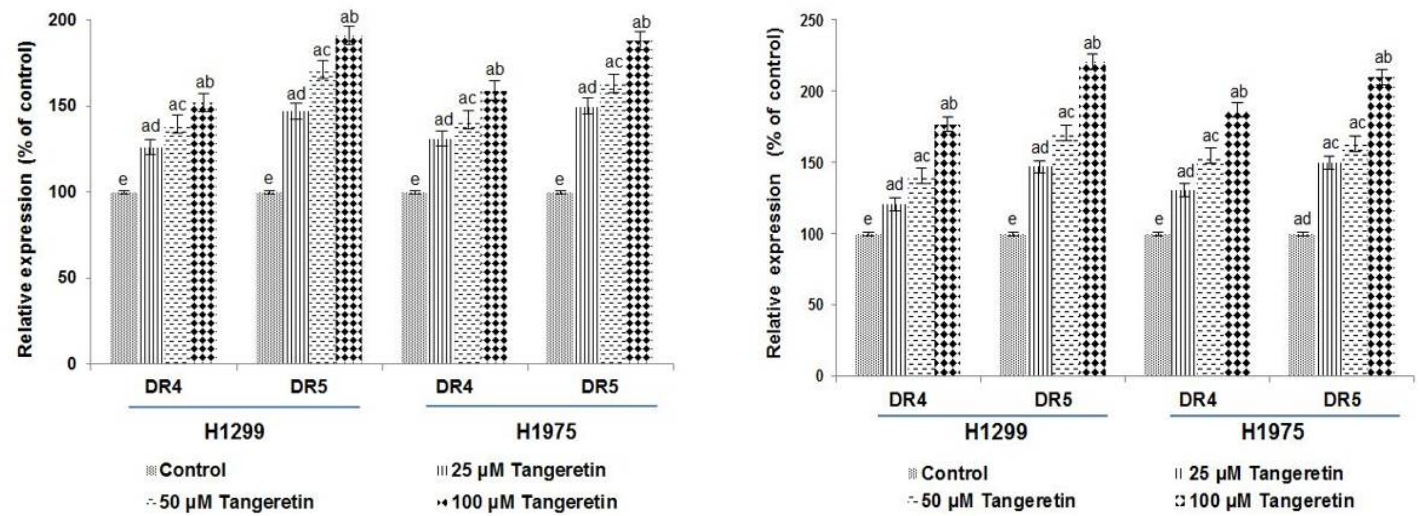

Figure 4: Influence of tangeretin on the expression of DR4 and DR5. Tangeretin potentially enhanced the cell surface expressions of DR4 and DR5 (a). Western blotting analysis revealed markedly up-regulated expressions of DR4 and DR5 protein levels by tangeretin (b) Results are expressed as means \pm SD with $n=6 . p<0.05$ versus control, denoted by ${ }^{a} ;{ }^{b-e}$ denotes mean values within the same group that differ from each other at $p<$ 0.05 on one-way ANOVA and DMRT analysis 
Influence of tangeretin on the expression of decoy receptors

The enhanced expression of antagonistic decoy receptors of TRAIL (DcR1 and DcR2) is reportedly involved in TRAIL resistance [12]. We observed that tangeretin, at all tested doses, was able to potentially supress the expression of DcR1 and DcR2.

However, the effects were more pronounced on DcR1 than DcR2, and the 100- $\mu \mathrm{M}$ dose exhibited maximal effects (Fig. 5). Thus, by downregulating DcR1 and DcR2 and inducing DR4/5 expression, tangeretin effectively aids in activating apoptosis of lung cancer cells.

\section{CHOP mediates tangeretin-induced up- regulation of death receptors}

It has been demonstrated that the induction of DRs by various stimulants is mediated through the activation of CHOP $[25,26]$. We investigated whether tangeretin influenced $\mathrm{CHOP}$ expression and whether CHOP is also involved in DR5 expression and tangeretin-induced apoptosis. RT-PCR analysis revealed enhanced DR5 and CHOP mRNA levels (Fig. $6 a$ and b). In line with the CHOP mRNA levels, western blot analysis also revealed significantly $(p<0.05)$ enhanced $\mathrm{CHOP}$ protein expression. These observations indicate a positive influence of tangeretin on CHOP expression.

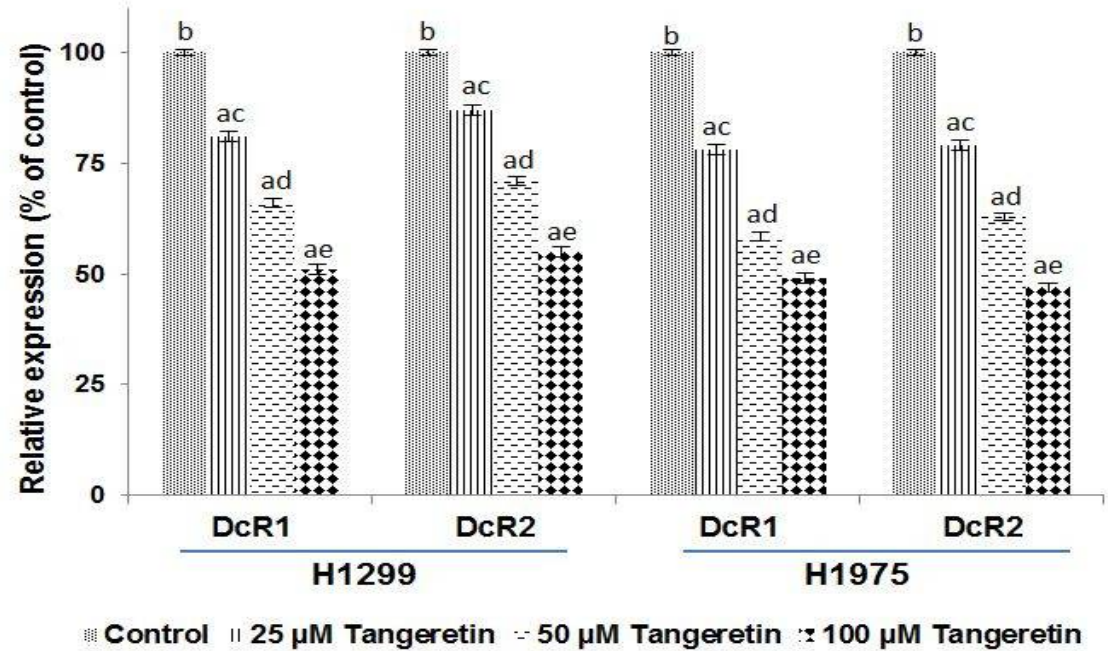

Figure 5: Tangeretin modulated decoy receptor expressions. Tangeretin effectively down-regulated the expressions of DcR1 and DcR2 dose-dependently. Results are expressed as means \pm SD with $n=3 . p<0.05$ versus control, denoted by ${ }^{a}$; ${ }^{b-e}$ denotes mean values within the same group that differ from each other at $p<$ 0.05 on one-way ANOVA and DMRT analysis

b

a

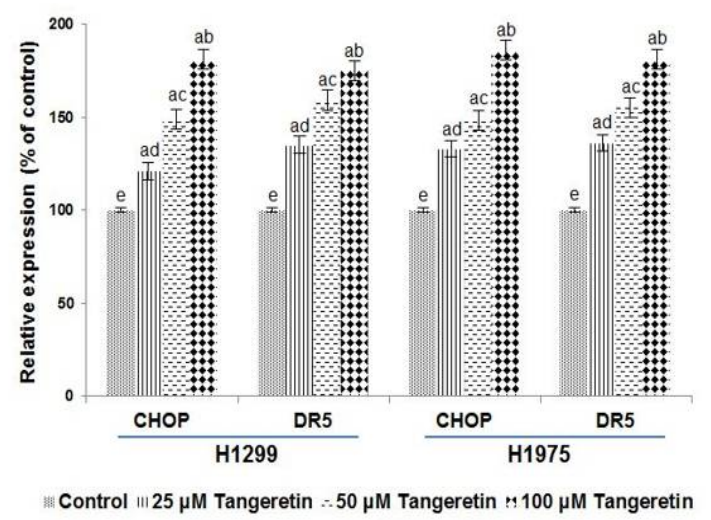

Figure 6: Influence of tangeretin on DR5 and CHOP expression. Tangeretin significantly up-regulated the mRNA levels of both CHOP and DR5 (a and b). Results are expressed as means \pm SD with $n=6 . p<0.05$ versus control, denoted by ${ }^{a} ;{ }^{b-e}$ denotes mean values within the same group that differ from each other at $p<0.05$ on one-way ANOVA and DMRT analysis (L1, Control; L2, $25 \mu \mathrm{M}$ tangeretin; L3, $50 \mu \mathrm{M}$ tangeretin; L4, $100 \mu \mathrm{M}$ tangeretin) 
siRNA was used to further confirm whether tangeretin was able to mediate DR5 expression via CHOP and to determine whether CHOP-DR5 is involved in tangeretin-mediated apoptosis. Interestingly, DR5 expression decreased upon transfection with CHOP siRNA (Fig. 7), and this decreased expression markedly affected the apoptosis percentage (Figs. 8 and 9). Significantly reduced apoptosis of lung cancer cells was observed on transfection with both CHOP siRNA and DR5 siRNA. However, tangeretin treatment considerably enhanced DR5 expression even in the presence of CHOP siRNA and enhanced the apoptosis percentage to some extent, while the percentage was lower than that in the absence of siRNA. These observations indicate that tangeretin-induced apoptosis occurs in part through direct stimulation of apoptosis and is in part mediated by CHOP. Additionally, $\mathrm{CHOP}$ is critical in DR5-mediated TRAIL-induced apoptosis.

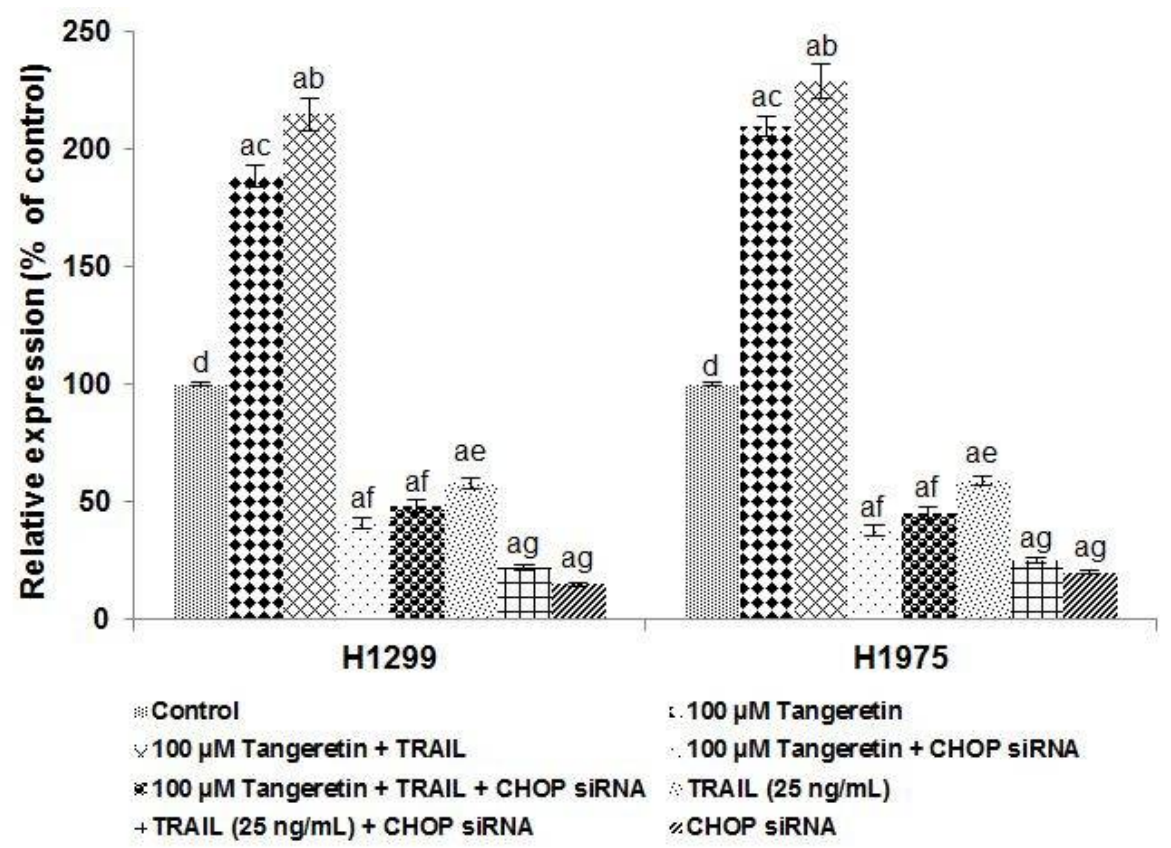

Figure 7: Tangeretin enhanced DR5 expression after transfection with CHOP siRNA. Results are expressed as means \pm SD with $n=6$. $p<0.05$ versuscontrol, denoted by ${ }^{a}$; ${ }^{b-g}$ denotes mean values within the same group that differ from each other at $p<0.05$ on one-way ANOVA and DMRT analysis

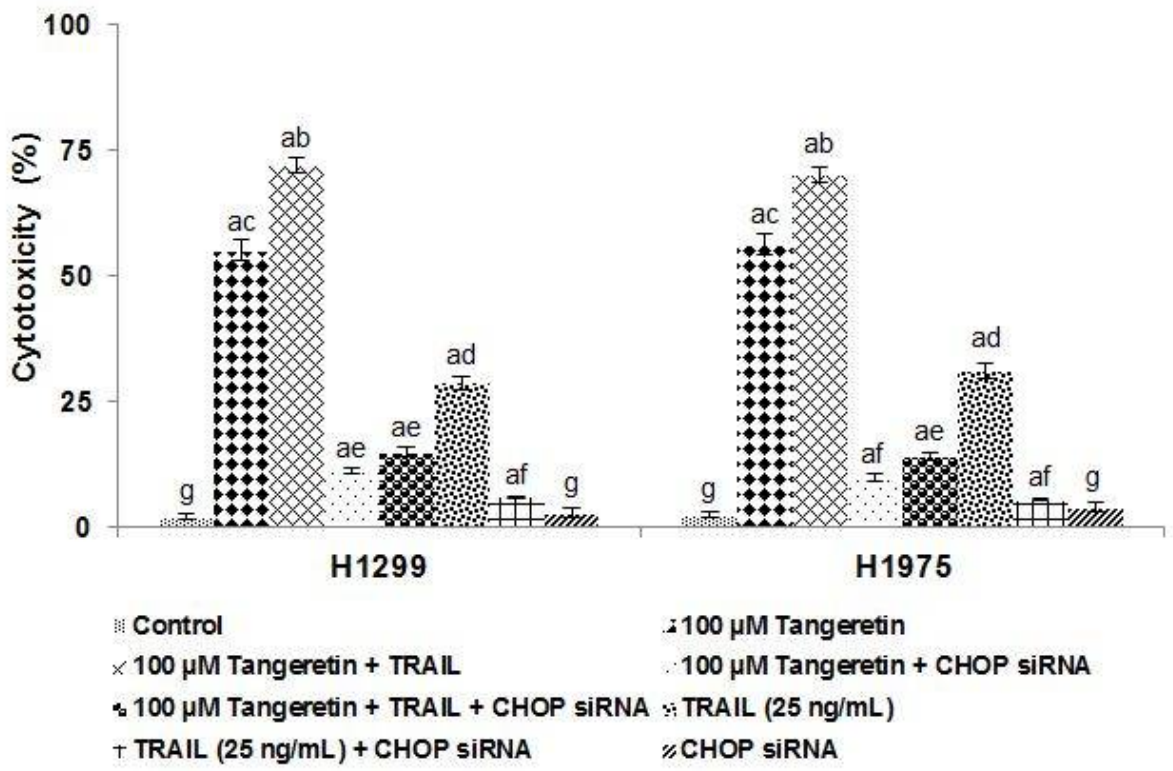

Figure 8: Tangeretin exposure increased the apoptosis percentage of human lung cancer cells following transfection with CHOP siRNA. Results are expressed as means \pm SD with $n=6 . p<0.05$ versus control, denoted by ${ }^{a} ;{ }^{b-g}$ denotes mean values within the same group that differ from each other at $p<0.05$ on one-way ANOVA and DMRT analysis 


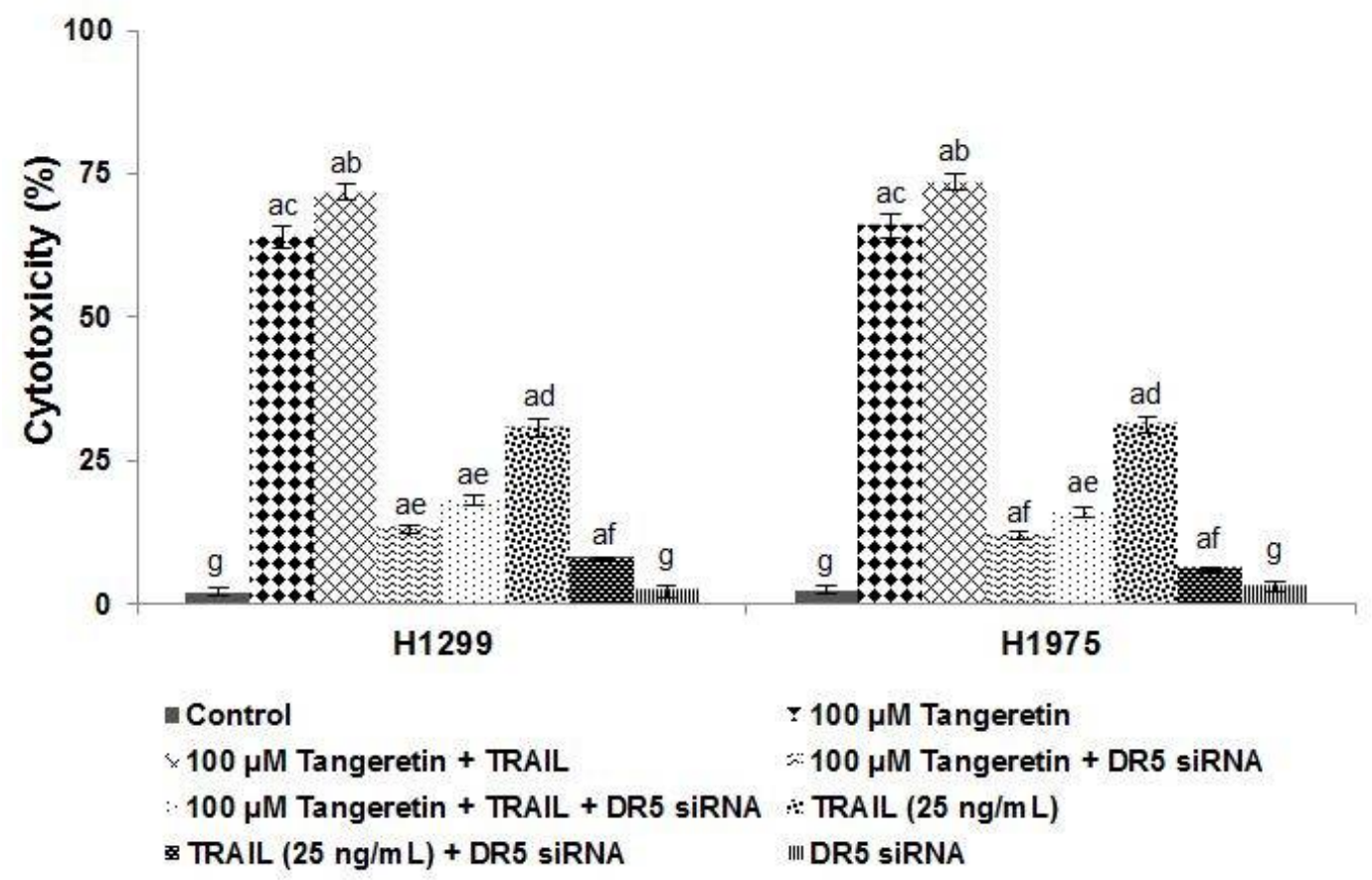

Figure 9: Tangeretin exposure significantly increased the apoptosis percentage following transfection with DR5 siRNA. Results are expressed as means $\pm S D$ with $n=6 . p<0.05$ versus control, denoted by ${ }^{a} ;{ }^{b-g}$ denotes mean values within the same group that differ from each other at $p<0.05$ on one-way ANOVA and DMRT analysis

Tangeretin modulates expression of various cell survival proteins

Numerous studies have demonstrated that overexpression of cell survival proteins, such as IAPs, survivin, cFLIP, Bcl-2, and $B c l-x L$, is involved in the development of TRAIL resistance $[27,28]$. We observed significantly $(p<0.05)$ increased expression of cell survival proteins in H1299 and H1975 cells (Figure 10). However, tangeretin treatment at 25,50 , or $100 \mu \mathrm{M}$

a

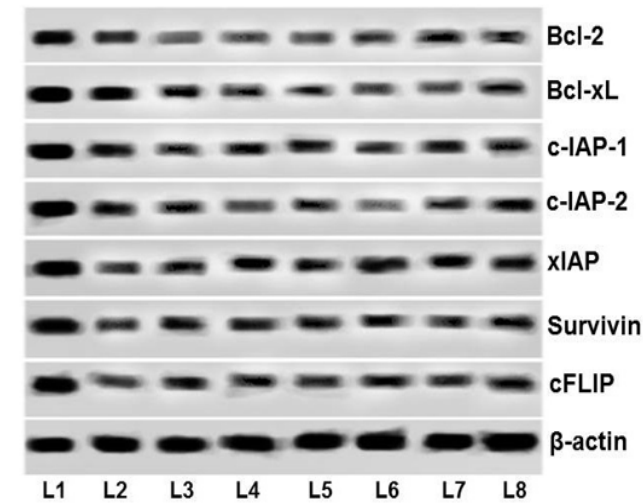

resulted in a decline in the expression levels in a dose-dependent manner.

\section{Tangeretin up-regulates expression of pro- apoptotic proteins}

We observed a remarkable increase $(p<0.05)$ in the expression of caspase- $3,-8$ and -9 in $\mathrm{H} 1299$ and $\mathrm{H} 1975$ cells on exposure to tangeretin (Fig. 11); pro-apoptotic protein Bax was also upregulated. The expression was dose-dependently regulated by tangeretin.

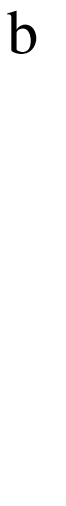

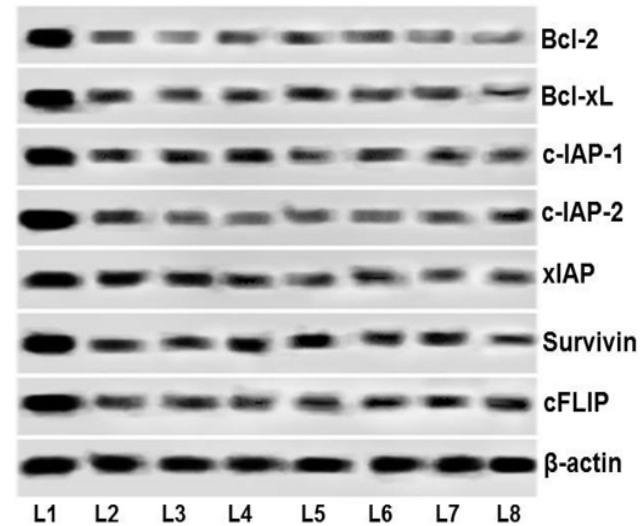

Figure 10: Tangeretin modulated the expressions of cell survival proteins. Tangeretin exposure caused marked down-regulation of cell survival proteins, eventually promoting apoptosis in lung cancer cells (a) H1299 (b) H1975 (L1, Control; L2, $100 \mu \mathrm{M}$ tangeretin; L3, $100 \mu \mathrm{M}$ tangeretin + TRAIL; L4, $100 \mu \mathrm{M}$ tangeretin + CHOP siRNA; L5, $100 \mu \mathrm{M}$ tangeretin + TRAIL + CHOP siRNA; L6, TRAIL $(25 \mathrm{ng} / \mathrm{mL}) ; \mathrm{L} 7$, TRAIL $(25 \mathrm{ng} / \mathrm{mL})+$ CHOP siRNA; L8, CHOP SiRNA) 


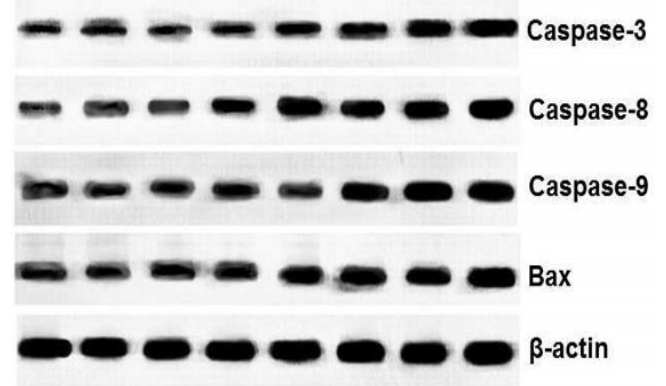

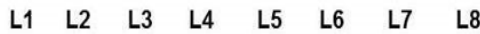

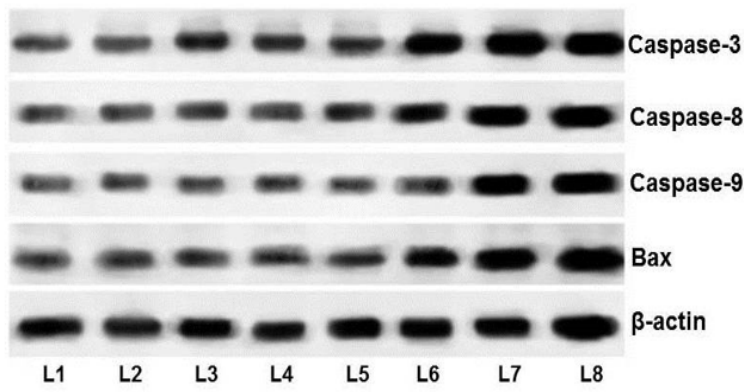

Figure 11: Tangeretin enhanced pro-apoptotic protein expression. Tangeretin markedly up-regulated the expressions of caspases and Bax, thus potentiating apoptosis in human lung cancer cells (a) $\mathrm{H} 1299$ and (b) H1975 (L1, Control; L2, $100 \mu \mathrm{M}$ tangeretin; L3, $100 \mu \mathrm{M}$ tangeretin + TRAIL; L4, $100 \mu \mathrm{M}$ tangeretin + CHOP siRNA; L5, $100 \mu \mathrm{M}$ tangeretin + TRAIL + CHOP siRNA; L6, TRAIL $(25 \mathrm{ng} / \mathrm{mL}) ; \mathrm{L} 7$, TRAIL $(25 \mathrm{ng} / \mathrm{mL})+\mathrm{CHOP}$ SiRNA; L8, CHOP SiRNA)

Tangeretin-induced up-regulation of TRAIL receptors is mediated by MAPKs

We investigated whether activation of MAPKs (JNK, ERK, and P38MAPK) is involved in tangeretin-induced DR5 induction. We observed a significant $(p<0.05)$ increase in the activation of ERK and JNK, as evidenced by raised phosphorylation levels. The $50-$ and $100-\mu \mathrm{M}$ doses were more effective in activating JNK and ERK than was the $25-\mu \mathrm{M}$ dose. Further, ERK levels were higher as against JNK. While the levels of p38 were noticeably increased by tangeretin, there was no significant increase, suggesting that the activation of JNK and ERK is involved more critically in tangeretin-mediated apoptosis than p38.

We also observed a drastic reduction in the expression of DR5 and DR4 in the presence of inhibitors of JNK (SP600125) and ERK1/2 (PD98059). However, the expression was not significantly affected by the presence of an inhibitor of p38 MAPK (SB202190). Tangeretin induced the expression of TRAIL receptors, even in the presence of inhibitors, in a dosedependent manner. These observations illustrate that the activation of JNK and ERK is more closely involved in the up-regulated expression of DR4 and DR5.

a

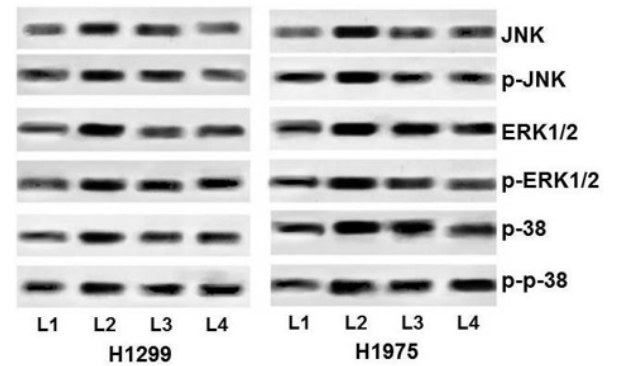

b

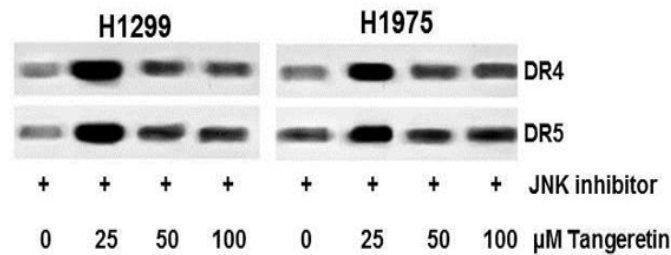

c

d
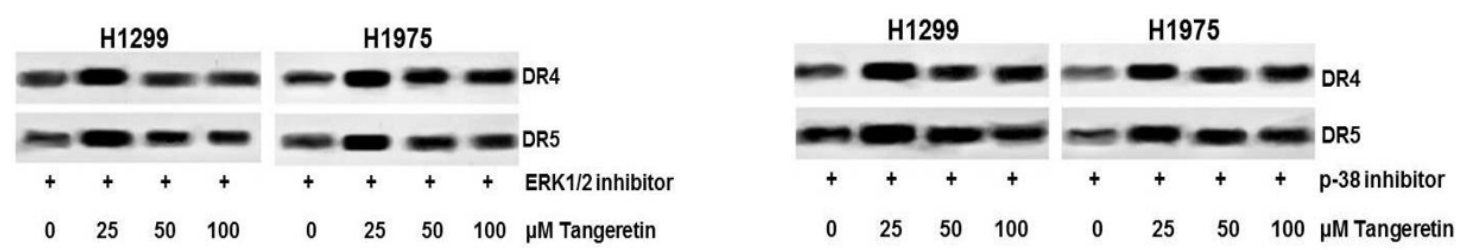

Figure 12: Tangeretin-mediated enhanced TRAIL-induced apoptosis involves MAPKs. Tangeretin exposure caused marked increases in the levels of JNK, ERK1/2, and p38 MAPK (a). Tangeretin-activated MAPKs potentially influenced DR4 and DR5 expression $(b-d)$. Tangeretin up-regulated DR4 and DR5 expressions even in the presence of specific MAPK inhibitors (L1, Control; L2, $25 \mu \mathrm{M}$ tangeretin; L3, $50 \mu \mathrm{M}$ tangeretin; L4, $100 \mu \mathrm{M}$ tangeretin) 


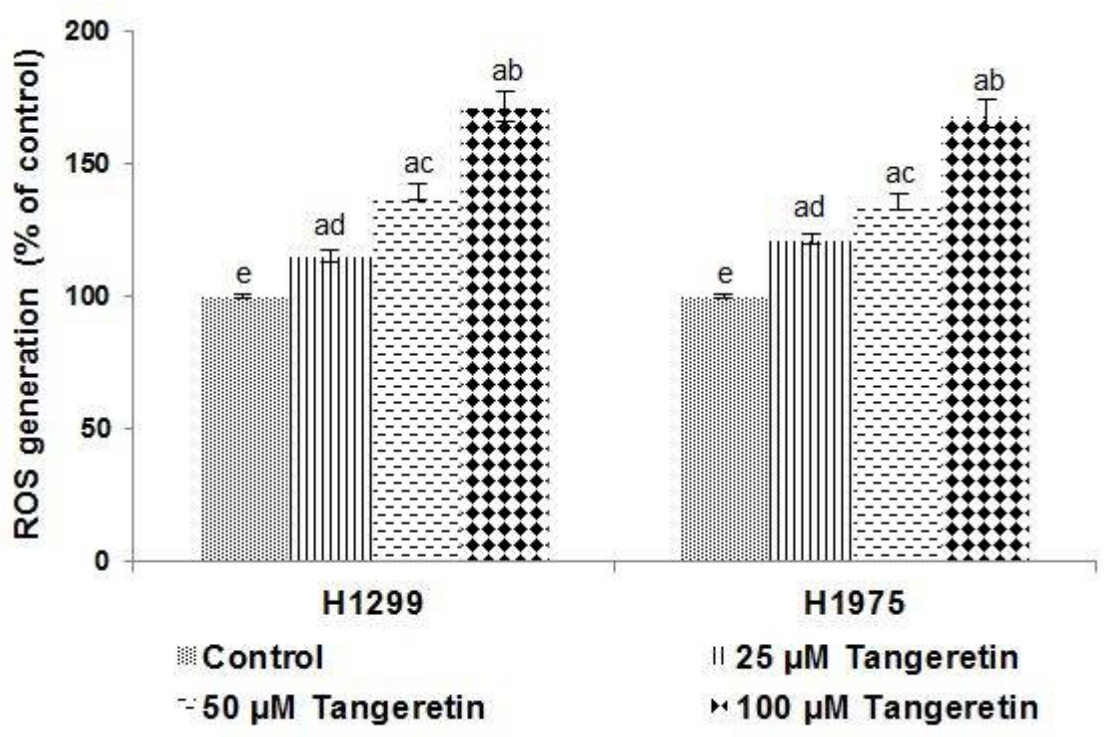

Figure 13: Tangeretin increased ROS levels in lung carcinoma cells. Results are expressed as means \pm SD with $\mathrm{n}=6$. $p<0.05$ versus control, denoted by ${ }^{\mathrm{a}} ;{ }^{\mathrm{b}-\mathrm{e}}$ denotes mean values within the same group that differ from each other at $p<0.05$ on one-way ANOVA and DMRT analysis

\section{Involvement of ROS in tangeretin-mediated TRAIL-induced apoptosis}

ROS are reportedly involved in the induction of DRs [20]. We observed enhanced ROS levels upon exposure to tangeretin (Fig. 13). The increase, however, was dose-dependent. These observations suggest the possible involvement of ROS in up-regulation of DRs and ERK/JNK MAPKs.

\section{DISCUSSION}

Despite the promising effects of TRAIL in cancer cell therapy, many reports have described human tumours developing resistance to TRAIL $[10,11]$ through various mechanisms. Altered expression of DRs and the Fas-associated death domain,as well as overexpression of antiapoptotic proteins, such as Bcl-2, survivin, cFLIP $[11,13,27,28]$, and XIAP, have been observed in many tumour cell lines exhibiting TRAIL resistance [28].

Thus, strategies to overcome this dysregulation and sensitise cells to TRAIL and possibly enhance its apoptotic effects are crucial and of tremendous value. Compounds of plant origin are known to effectively sensitise cells to TRAILinduced cancer cell cytotoxicity $[15,20]$. Here, we investigated whether tangeretin was able to sensitise and enhance TRAIL-induced apoptosis in the human lung cancer cells H1299 and $\mathrm{H} 1975$.

Treatment with tangeretin at 25 to $100 \mu \mathrm{M}$ reduced the viability of $\mathrm{H} 1299$ and $\mathrm{H} 1975$ cells, indicating its potent anti-proliferative efficacy.
The combined exposure to TRAIL and tangeretin dramatically increased the apoptotic cell counts compared with treatment with tangeretin or TRAIL separately. This suggests that tangeretin was able to effectively enhance the effects of TRAIL; in addition, tangeretin down-regulated the cell survival proteins $\mathrm{Bcl}-2$, Bcl-xL, xIAP, cFLIP, ClAP-1, ClAP-2, and survivin. These proteins have been reported to be associated with TRAIL resistance $[27,28]$. Thus, decreased expression of anti-apoptotic proteins aids in TRAIL-induced apoptosis. Previous studies have demonstrated that down-regulation of survivin, $\mathrm{Bcl}-\mathrm{xL}$, and $\mathrm{Bcl}-$ 2 promotes sensitivity to TRAIL $[27,28]$.

XIAP contributes to TRAILresistance by inhibiting caspase-3, -7, and -9 [28], and cFLIP inhibits caspase activation by competing for the Fasassociated death domain [13]. Thus, effective suppression of CFLIP and IAPs by tangeretin could potentially contribute to sensitising cancer cells to TRAIL. In the present study, elevated levels of caspase- $3,-8$ and -9 were observed upon tangeretin exposure. This up-regulated expression could be due to the inhibition of XIAP and CFLIP. Increased expression of the proapoptotic protein Bax also aids in enhancing TRAIL-mediated apoptosis. The modulations observed in the expression patterns were dosedependent, with $100-\mu \mathrm{M}$ of tangeretin exhibiting maximal effects; further combination with TRAIL showed an additional influence. Phytochemicals, such asguggulsterone and nimbolide [15,25], enhanced TRAIL-mediated cell death via upregulation of caspases and suppression of cell survival proteins. 
Binding of TRAIL with the death receptors DR4 and DR5 triggers TRAIL-induced apoptotic signalling, leading to the activation of executor caspase. Dysregulated expression levels have been reported in several TRAIL-resistant cancers [29], and subsequent up-regulation of the receptors promotes apoptosis [11,25]. Significantly up-regulated cell surface expression of DR4 and DR5 was observed upon tangeretin treatment. While tangeretin exposure caused elevated expression of DR4 and DR5, the expression of TRAIL decoy receptors DcR1 and DcR2 was dose-dependently reduced at the protein level. Mellier et al [30] showed that sensitivity to TRAIL-mediated apoptosis is influenced by the over-expression of TRAILdecoy receptors. The down-regulated expression of DcR1 and DcR2, along with elevated DR4 and DR5 expression upon exposure to tangeretin, effectively contributes to enhance TRAILmediated apoptosis.

Furthermore, DR5 expression was up-regulated by tangeretin even at the gene level, as evidenced by increased DR5mRNA levels. The mRNA levels of CHOP were also enhanced upon tangeretin exposure. $\mathrm{CHOP}$ is a key transcriptional factor that regulates DR5. CHOP binds to the DR5 promoter region and upregulates DR5 expression [17]. The enhanced CHOP levels on tangeretin exposure suggest that tangeretin modulates DR5 expression via $\mathrm{CHOP}$. This was further confirmed when $\mathrm{CHOP}$ expression was silenced using CHOP siRNA, which resulted in significant inhibition of DR5 expression; however, tangeretin was able to considerably enhance DR5 expression even with CHOP siRNA. Silencing of DR5 and CHOP genes resulted in a sharp decline in apoptosis levels, reflecting the vital roles of DR5 and CHOP in TRAIL-mediated cell death. To an extent, tangeretin exposure was able to increase the apoptosis levels even in the presence of DR5 siRNA and CHOP siRNA. These observations suggest that tangeretin was able to potentiate the apoptosis-mediating effects of TRAIL by modulating DR5 and CHOP.

We also observed that tangeretin was able to induce ROS production in $\mathrm{H} 1299$ and $\mathrm{H} 1975$ cells. The observed ROS levels could have also induced CHOP expression, because CHOP is a major stress-regulated protein [25]. Several studies have reported that chemotherapeutic agents enhance DR5 expression and TRAILmediated apoptosis via ROS-dependent pathways [15,25,26].

ROS reportedly trigger various signal transduction pathways that are involved in cell growth, differentiation, or death. MAPKs are important downstream mediators of ROSinduced signalling [26]. ERK, JNK, and p38 MAPK have been found to be activated in TRAILmediated apoptosis $[15,30]$ and are involved in TRAIL receptor induction [15,26]. In our study, the significant increases in the activation of JNK and ERK, along with a considerable increase in p38 MAPK activation on exposure to tangeretin, could have been either due to direct stimulation of tangeretin and/or in part indirectly due to ROS. We also observed suppression of DR4 and DR5 in the presence MAPK inhibitors, which was noticeably enhanced by tangeretin.

\section{CONCLUSION}

Tangeretin up-regulates death receptors and enhances TRAIL-mediated apoptosis via ROS$\mathrm{CHOP}$ signalling and MAPKs. Thus, tangeretin should be further explored as a potent candidate for combined therapy with TRAIL for induction of apoptosis of cancer cells.

\section{DECLARATIONS}

\section{Acknowledgement}

This work was supported by a grant from Beijing Natural Science Foundation (no. 7142152).

\section{Conflict of Interest}

No conflict of interest associated with this work.

\section{Contribution of Authors}

The authors declare that this work was done by the authors named in this article and all liabilities pertaining to claims relating to the content of this article will be borne by them.

\section{Open Access}

This is an Open Access article that uses a funding model which does not charge readers or their institutions for access and distributed under the terms of the Creative Commons Attribution License (http://creativecommons.org/licenses/by 14.0) and the Budapest Open Access Initiative (http://www.budapestopenaccessinitiative.org/rea d), which permit unrestricted use, distribution, and reproduction in any medium, provided the original work is properly credited.

\section{REFERENCES}

1. Siegel R, Ma J, Zou Z, Jemal A. Cancer statistics, 2014. CA Cancer J Clin 2014; 64: e9-e29. 
2. Herbst RS, Heymach JV, Lippman SM. Lung cancer. N Engl J Med 2008; 359: 1367-1380.

3. Brambilla E, Gazdar A. Pathogenesis of lung cancer signalling pathways: roadmap for therapies. EurRespir $J$ 2009; 33: 1485-1497.

4. Ashkenazi A, Pai RC, Fong S, Leung S, Lawrence DA, Marsters SA, Blackie C, Chang L, McMurtrey AE, Hebert $A$, et al. Safety and antitumor activity of recombinant soluble Apo2 ligand. J Clin Invest 1999; 104: 155-162.

5. Sheridan JP, Marsters SA, Pitti RM, Gurney A, Skubatch $M$, Baldwin D, Ramakrishnan L, Gray CL, Baker K, Wood WI, et al. Control of TRAIL-induced apoptosis by a family of signaling and decoy receptors. Science 1999; 277: 818-821.

6. Pan G, Ni J, Wei YF, Yu G, Gentz R, Dixit V M. An antagonist decoy receptor and a death domaincontaining receptor for TRAIL. Science 1997; 277: 815818.

7. Degli-Esposti MA, Dougall WC, Smolak PJ, Waugh JY, Smith CA, Goodwin RG. The novel receptor TRAIL-R4 induces NF-kappaB and protects against TRAILmediated apoptosis, yet retains an incomplete death domain. Immunity 1997a; 7: 813-820.

8. Emery JG, McDonnell P, Burke MB, Deen KC, Lyn S, Silverman C, Dul E, Appelbaum ER, Eichman C, DiPrinzio $R$, et al. Osteoprotegerin is a receptor for the cytotoxic ligand TRAIL. J Biol Chem 1998; 273: 14363 14367.

9. Nagata S. Apoptosis by death factor. Cell 1997; 88: 355365.

10. Ashkenazi A, Dixit VM. Death receptors: signaling and modulation. Science 1998; 281: 1305-1308.

11. Zhang L, Fang B. Mechanisms of resistance to TRAILinduced apoptosis in cancer. Cancer Gene Ther 2005; 12: 228-237.

12. Sanlioglu $A D$, Dirice E, Aydin C, Erin N, Koksoy S, Sanlioglu S. Surface TRAIL decoy receptor-4 expression is correlated with TRAIL resistance in MCF7 breast cancer cells. BMC Cancer 2005; 5: 54.

13. Irmler M, Thome M, Hahne M, Schneider $P$, Hofmann $K$, Steiner V, Bodmer JL, Schröter M, Burns K, Mattmann $C$, et al. Inhibition of death receptor signals by cellular FLIP. Nature 1997; 388: 190-195.

14. Griffith TS, Kucaba TA, O'Donnell MA, Burns J, Benetatos C, McKinlay MA, Condon S, Chunduru S. Sensitization of human bladder tumor cells to TNF related apoptosis-inducing ligand (TRAIL)-induced apoptosis with a small molecule IAP antagonist. Apoptosis 2011; 16: 13-26.

15. Gupta SC, Reuter S, Phromnoi K, Park B, Hema PS, Nair M, Aggarwal BB. Nimbolide sensitizes human colon cancer cells to TRAIL through reactive oxygen speciesand ERK-dependent up-regulation of death receptors, p53 and Bax. J Biol Chem 2011; 286: 1134-1146.

16. Gupta SC, Francis SK, Nair MS, Mo YY, Aggarwal BB. Azadirone, a limonoidtetranortriterpene, induces death receptors and sensitizes human cancer cells to tumor necrosis factor-related apoptosis-inducing ligand (TRAIL) through a p53 protein-independent mechanism. J Biol Chem 2013; 288: 32343-32356

17. Lin N, Sato T, Takayama Y, Mimaki Y, Sashida Y, Yano $M$, Ito A. Novel anti-inflammatory actions of nobiletin, a citrus polymethoxy flavonoid, on human synovial fibroblasts and mouse macrophages. Biochem Pharmacol 2003; 65: 2065-2071.

18. Kawaii S, Tomono Y, Katase E, Ogawa K, Yano M. Antiproliferative activity of flavonoids on several cancer cell lines. Biosci Biotech Biochem 1999a; 63: 896-899.

19. Datla KP, Christidou M, Widmer WW, Rooprai HK, Dexter $D T$. Tissue distribution and neuroprotective effects of citrus flavonoid tangeretin in a rat model of Parkinson's disease. Neuroreport 2001; 12: 3871-3875.

20. Prasad S, Yadav VR, Kannappan R, Aggarwal BB. Ursolic Acid, a pentacyclintriterpene, potentiates TRAILinduced apoptosis through p53-independent upregulation of death receptors evidence for the role of reactive oxygen species and JNK. J Biol Chem 2011; 286: 5546-5557.

21. Yadav VR, Prasad S, Kannappan R, Ravindran J, Chaturvedi MM, Vaahtera L, Parkkinen J, Aggarwal BB. Cyclodextrin-complexedcurcumin exhibits antiinflammatory and antiproliferative activities superior to those of curcumin through higher cellular uptake. BiochemPharmacol 2010a; 80: 1021-1032.

22. Yadav VR, Sung B, Prasad S, Kannappan R, Cho SG, Liu M, Chaturvedi MM, Aggarwal BB. Celastrol suppresses invasion of colon and pancreatic cancer cells through the down-regulation of expression of CXCR4 chemokine receptor. J Mol Med 2010b; 88: 1243-1253

23. Sandur SK, Pandey MK, Sung B, Ahn KS, Murakami A, Sethi G, Limtrakul $P$, Badmaev V, Aggarwal BB. Curcumin, demethoxycurcumin, bis-demethoxycurcumin, tetrahydrocurcumin and turmerones differentially regulate anti-inflammatory and antiproliferative responses through a ROS-independent mechanism. Carcinogenesis 2007; 28: 1765-1773.

24. Yang J, Yang Y, Tian L, Sheng XF, Liu F, Cao JG. Casticin-induced apoptosis involves death receptor 5 upregulation in hepatocellular carcinoma cells. World $J$ Gastroenterol 2011; 17: 4298-4307.

25. Moon DO, Park SY, Choi YH, Ahn JS, Kim GY. Guggulsterone sensitizes hepatoma cells to TRAILinduced apoptosis through the induction of CHOPdependent DR5: Involvement of ROS-dependent ERstress. Biochem Pharmacol 2011; 82: 1641-1650.

26. Sung B, Ravindran J, Prasad S, Pandey MK, Aggarwal $B B$. Gossypol induces death receptor-5 through activation of the ROS-ERK-CHOP pathway and sensitizes colon cancer cells to TRAIL. J Biol Chem 2010; 285: 35418-35427.

27. Chawla-Sarkar M, Bae SI, Reu FJ, Jacobs BS, Lindner $D J$, Borden EC. Down-regulation of BCl-2, FLIP or IAPS (XIAP and survivin) by siRNAs sensitizes resistant 
melanoma cells to Apo2L/TRAIL-induced apoptosis. Cell Death Differ 2004; 11: 915-923.

28. Deveraux QL, Takahashi R, Salvesen GS, Reed JC. Xlinked IAP is a direct inhibitor of cell-death proteases. Nature 1997; 388: 300-304.

29. Fisher MJ, Virmani AK, Wu L, Aplenc R, Harper JC, Powell SM, Rebbeck TR, Sidransky D, Gazdar AF, El-
Deiry WS. Nucleotide substitution in the ectodomain of trail receptor DR4 is associated with lung cancer and head and neck cancer. Clin Cancer Res 2001; 7: 16881697.

30. Mellier G, Huang S, Shenoy K, Pervaiz S. TRAlLing death in cancer. Mol Aspects Med 2010; 31: 93-112. 